\title{
Evaluation of the highly-cited researchers' database for a country: Proposals for meaningful analyses on the example of Germany
}

\author{
Lutz Bornmann* \& Johann Bauer**
}

*corresponding author:

Division for Science and Innovation Studies

Administrative Headquarters of the Max Planck Society

Hofgartenstr. 8,

80539 Munich, Germany.

Email: bornmann@gv.mpg.de

** Max Planck Institute of Biochemistry

Am Klopferspitz 18,

82152 Martinsried, Germany.

Email: jbauer@biochem.mpg.dem 


\begin{abstract}
In 2014 Thomson Reuters (TR, provider of the Web of Science, WoS) published a list of highly-cited researchers worldwide. This includes those scientists who have published the most papers in their discipline which belong to the $1 \%$ of the most-cited papers. Bornmann and Bauer (in press) have presented a first evaluation in which the scientists are evaluated on the basis of their affiliations. In this short communication we would like to indicate how the TR data can be used to perform a meaningful country-specific evaluation. Germany serves as the example for the analysis.
\end{abstract}

\title{
Keywords
}

bibliometrics; highly cited researchers; Thomson Reuters 


\section{Introduction}

In 2014 Thomson Reuters (TR, provider of the Web of Science, WoS) published a list of highly-cited researchers worldwide (http://highlycited.com/). This includes those scientists who have published the most papers in their discipline which belong to the $1 \%$ of the mostcited papers. The great advantage of the TR data consists in their being standardised with regard to time (publication range from 2002 to 2012), the document type (only "articles" and "reviews") and the discipline (the rankings of the researchers are produced within a discipline). The data therefore not only provide an overview over research excellence on the level of individual researchers, but they can also be evaluated on a higher aggregation level.

Bornmann and Bauer (in press) have presented a first evaluation in which the scientists are evaluated on the basis of their affiliations. In this short communication we would like to indicate how the TR data can be used to perform a meaningful country-specific evaluation. Germany serves as the example for the analysis.

\section{Methods}

In order to identify the highly-cited researchers, TR evaluates the publications with the document types "article" and "review" in journals of the natural and social sciences and the humanities published between 2002 and 2012. Of these publications, TR determines those which belong to the $1 \%$ of the most-cited publications in their subject area and publication year (Bornmann \& Bauer, in press). The authors of these highly cited publications were categorized under the discipline (e.g. materials science; see http://in-cites.com/thresholdscitation.html) associated with the journals where their highly cited publications appeared. A ranking order was established within a discipline. The more highly cited publications a researcher had, the higher was their rank in the discipline. The list of the highly cited researchers published under the URL above includes those researchers whose ranking is equal 
to or greater than the square root of the population (of all researchers in a discipline with at least one highly cited publication).

The evaluations presented below are based on the primary addresses of the researchers. As the analyses of the addresses in Bornmann and Bauer (in press) have shown, the inclusion of additional addresses for the researchers leads to results which have hardly anything to do with research quality. Thus King Abdulaziz University, Saudi Arabia, lands in second place in a worldwide institution ranking which takes into account all the addresses for highly cited researchers (i.e. in front of Harvard University and the University of Stanford). When only the primary addresses of the researchers were used, King Abdulaziz University performed much worse (Gingras, 2014).

Whereas the analyses of Bornmann and Bauer (in press) assess the institutes of larger organisations, such as those of the Max Planck Society, in combination, the current study analyses the organisations' individual institutions separately. The separation was performed because this study is also looking into regional distributions, and the institutes of an organisation are frequently distributed regionally.

\section{Results}

The TR database contains a total of 3215 researchers worldwide. Table 1 shows the distribution of the researchers by country. As the results show, more than half the researchers work in the USA; a further $\sim 10 \%$ in Great Britain. Germany, with 164, has around $5 \%$ of the researchers. Similar results have been published by Myklebust (2014).

Table 1. Distribution of highly cited researchers by country. The table only includes countries with at least ten researchers.

\begin{tabular}{|l|l|l|l|}
\hline Country & absolute frequency & per cent & Cumulative share \\
\hline USA & 1,701 & 52.91 & 52.91 \\
\hline UK & 303 & 9.42 & 62.33 \\
\hline Germany & 164 & 5.10 & 67.43 \\
\hline China & 160 & 4.98 & 72.41 \\
\hline
\end{tabular}




\begin{tabular}{|l|l|l|l|}
\hline Japan & 98 & 3.05 & 75.46 \\
\hline Canada & 89 & 2.77 & 78.23 \\
\hline France & 84 & 2.61 & 80.84 \\
\hline Netherlands & 76 & 2.36 & 83.20 \\
\hline Switzerland & 67 & 2.08 & 85.29 \\
\hline Australia & 65 & 2.02 & 87.31 \\
\hline Italy & 52 & 1.62 & 88.93 \\
\hline Spain & 43 & 1.34 & 90.26 \\
\hline Saudi Arabia & 33 & 1.03 & 91.29 \\
\hline Belgium & 32 & 1.00 & 92.29 \\
\hline Sweden & 28 & 0.87 & 93.16 \\
\hline Denmark & 27 & 0.84 & 94.00 \\
\hline South Korea & 21 & 0.65 & 94.65 \\
\hline Austria & 19 & 0.59 & 95.24 \\
\hline Finland & 14 & 0.44 & 95.68 \\
\hline Singapore & 14 & 0.44 & 96.11 \\
\hline Ireland & 12 & 0.37 & 96.49 \\
\hline Iceland & 11 & 0.34 & 96.83 \\
\hline Iran & 11 & 0.34 & 97.17 \\
\hline Israel & 10 & 0.31 & 97.48 \\
\hline Turkey & 10 & 0.31 & 97.79 \\
\hline Remaining countries & 71 & 2.21 & 100.00 \\
\hline Total & 3215 & 100.00 & \\
\hline
\end{tabular}

Table 2. Distribution of highly cited researchers from Germany by discipline

\begin{tabular}{|l|l|l|l|l|l|}
\hline \multirow{2}{*}{ Discipline } & Germany & \multicolumn{2}{l|}{ Worldwide } & Difference \\
\cline { 2 - 6 } & absolute & per cent & absolute & per cent & per \\
\hline Plant \& Animal Science & 18 & 10.98 & 176 & 5.47 & 5.51 \\
\hline Materials Science & 14 & 8.54 & 147 & 4.57 & 3.97 \\
\hline Chemistry & 16 & 9.76 & 198 & 6.16 & 3.6 \\
\hline Agricultural Sciences & 9 & 5.49 & 112 & 3.48 & 2.01 \\
\hline Physics & 10 & 6.1 & 144 & 4.48 & 1.62 \\
\hline Space Science & 8 & 4.88 & 106 & 3.3 & 1.58 \\
\hline Computer Science & 7 & 4.27 & 117 & 3.64 & 0.63 \\
\hline Environment/Ecology & 8 & 4.88 & 137 & 4.26 & 0.62 \\
\hline Geosciences & 9 & 5.49 & 159 & 4.95 & 0.54 \\
\hline Clinical Medicine & 20 & 12.2 & 402 & 12.5 & -0.3 \\
\hline Immunology & 3 & 1.83 & 87 & 2.71 & -0.88 \\
\hline $\begin{array}{l}\text { Pharmacology \& } \\
\text { Toxicology }\end{array}$ & 5 & 3.05 & 133 & 4.14 & -1.09 \\
\hline Economics \& Business & 3 & 1.83 & 95 & 2.95 & -1.12 \\
\hline Mathematics & 3 & 1.83 & 99 & 3.08 & -1.25 \\
\hline Biology \& Biochemistry & 7 & 4.27 & 195 & 6.07 & -1.8 \\
\hline Psychiatry/Psychology & 2 & 1.22 & 100 & 3.11 & -1.89 \\
\hline $\begin{array}{l}\text { Molecular Biology \& } \\
\text { Genetics }\end{array}$ & 7 & 4.27 & 201 & 6.25 & -1.98 \\
\hline Engineering & 6 & & & & \\
\hline Neuroscience \& & 3 & 1.83 & 129 & 4.01 & -2.18 \\
\hline
\end{tabular}




\begin{tabular}{|l|l|l|l|l|l|}
\hline Behaviour & & & & & \\
\hline Microbiology & 2 & 1.22 & 114 & 3.55 & -2.33 \\
\hline Social Sciences, general & 4 & 2.44 & 177 & 5.51 & -3.07 \\
\hline Total & 164 & 100.00 & 3215 & 100.00 & \\
\hline
\end{tabular}

Table 2 shows the results of the analysis with respect to the disciplines associated with the researchers (or their publications) from Germany. The table shows that the researchers are particularly often associated with the disciplines "Clinical Medicine" ( 12\%), "Plant \& Animal Science" $(\sim 11 \%)$ and "Chemistry" $(\sim 10 \%)$. In order to give an impression which disciplines are particularly often represented by researchers in Germany, the table also includes two columns with the numbers of the worldwide distribution. As shown by the difference between the per cent values for all researchers and those from Germany, researchers from Germany are especially over-represented in "Plant \& Animal Science" (5.51\%), "Materials Science" (3.97\%) and "Chemistry" (3.6\%) and under-represented in "Microbiology" (-2.33\%) and "Social Sciences, general" (-3.07\%).

Table 3. Distribution of highly cited researchers from Germany by Federal State

\begin{tabular}{|l|l|l|l|}
\hline Federal State & Number & Per cent & Cumulative per cent \\
\hline Bavaria & 35 & 21.47 & 21.47 \\
\hline Baden-Württemberg & 34 & 20.86 & 42.33 \\
\hline North Rhine-Westphalia & 23 & 14.11 & 56.44 \\
\hline Brandenburg & 10 & 6.13 & 62.58 \\
\hline Hesse & 10 & 6.13 & 68.71 \\
\hline Rhineland-Palatinate & 10 & 6.13 & 74.85 \\
\hline Thuringia & 8 & 4.91 & 79.75 \\
\hline Saxony & 7 & 4.29 & 84.05 \\
\hline Berlin & 6 & 3.68 & 87.73 \\
\hline Lower Saxony & 6 & 3.68 & 91.41 \\
\hline Saxony-Anhalt & 4 & 2.45 & 93.87 \\
\hline Hamburg & 3 & 1.84 & 95.71 \\
\hline Schleswig-Holstein & 3 & 1.84 & 97.55 \\
\hline Bremen & 2 & 1.23 & 98.77 \\
\hline Mecklenburg-Vorpommern & 1 & 0.61 & 99.39 \\
\hline Saarland & 1 & 0.61 & 100.00 \\
\hline Total & 163 & 100.00 & \\
\hline
\end{tabular}


Table 3 shows the distribution of the highly cited researchers across the Federal States in Germany. In this assessment, one researcher could not be included since their institutional data could not be verified. As the results in the table show, around half of the researchers come from two (out of 16) federal states: Bayern (35 researchers) and Baden-Württemberg (34 researchers).

Table 4. Distribution of highly cited researchers from Germany by city. Only cities with at least four researchers are included.

\begin{tabular}{|l|l|l|l|}
\hline City & Number & Per cent & Cumulative per cent \\
\hline Greater Munich & 27 & 16.56 & 16.56 \\
\hline Greater Berlin & 16 & 9.82 & 26.38 \\
\hline Heidelberg & 16 & 9.82 & 36.20 \\
\hline Mainz & 9 & 5.52 & 41.72 \\
\hline Stuttgart & 7 & 4.29 & 46.01 \\
\hline Bonn & 5 & 3.07 & 49.08 \\
\hline Jena & 5 & 3.07 & 52.15 \\
\hline Aachen & 4 & 2.45 & 54.60 \\
\hline Frankfurt & 4 & 2.45 & 57.06 \\
\hline Hanover & 4 & 2.45 & 59.51 \\
\hline Cologne & 4 & 2.45 & 61.96 \\
\hline Leipzig & 4 & 2.45 & 64.42 \\
\hline Nuremberg/Erlangen & 4 & 2.45 & 66.87 \\
\hline Ulm & 4 & 2.45 & 69.33 \\
\hline Remaining cities & 50 & 30.77 & 100.00 \\
\hline Total & 163 & 100.00 & \\
\hline
\end{tabular}

Table 4 shows the distribution of highly cited researchers from Germany by city. In this analysis too, one researcher could not be included since their institutional data could not be verified. For Munich and Berlin, a greater area was formed in which, for example, Martinsried is associated with Munich and Potsdam with Berlin. As the results in the table show, around half of the researchers come from six (out of 45) cities: The most researchers come from greater Munich (with 27 researchers) and greater Berlin or Heidelberg (each with 16 researchers). 
Table 5. Distribution of highly cited researchers from greater Munich by discipline

\begin{tabular}{|c|c|c|c|c|c|}
\hline \multirow[t]{2}{*}{ Discipline } & \multicolumn{2}{|c|}{ Greater Munich } & \multicolumn{2}{|l|}{ Germany } & \multirow{2}{*}{$\begin{array}{l}\text { Difference } \\
\text { per cent }\end{array}$} \\
\hline & absolute & Per cent & absolute & Per cent & \\
\hline Molecular Biology \& Genetics & 5 & 18.52 & 7 & 4.29 & 14.23 \\
\hline Space Science & 4 & 14.81 & 8 & 4.91 & 9.9 \\
\hline Physics & 4 & 14.81 & 10 & 6.13 & 8.68 \\
\hline Psychiatry/Psychology & 2 & 7.41 & 2 & 1.23 & 6.18 \\
\hline Computer Science & 2 & 7.41 & 7 & 4.29 & 3.12 \\
\hline Immunology & 1 & 3.7 & 3 & 1.84 & 1.86 \\
\hline Mathematics & 1 & 3.7 & 3 & 1.84 & 1.86 \\
\hline Social Sciences, general & 1 & 3.7 & 4 & 2.45 & 1.25 \\
\hline Pharmacology \& Toxicology & 1 & 3.7 & 5 & 3.07 & 0.63 \\
\hline Engineering & 1 & 3.7 & 6 & 3.68 & 0.02 \\
\hline Biology \& Biochemistry & 1 & 3.7 & 7 & 4.29 & -0.59 \\
\hline Clinical Medicine & 3 & 11.11 & 20 & 12.27 & -1.16 \\
\hline Microbiology & 0 & 0 & 2 & 1.23 & -1.23 \\
\hline Economics \& Business & 0 & 0 & 3 & 1.84 & -1.84 \\
\hline Neuroscience \& Behavior & 0 & 0 & 3 & 1.84 & -1.84 \\
\hline Environment/Ecology & 0 & 0 & 8 & 4.91 & -4.91 \\
\hline Geosciences & 0 & 0 & 8 & 4.91 & -4.91 \\
\hline Agricultural Sciences & 0 & 0 & 9 & 5.52 & -5.52 \\
\hline Plant \& Animal Science & 1 & 3.7 & 18 & 11.04 & -7.34 \\
\hline Materials Science & 0 & 0 & 14 & 8.59 & -8.59 \\
\hline Chemistry & 0 & 0 & 16 & 9.82 & -9.82 \\
\hline Total & 27 & 100.00 & 163 & 100.00 & \\
\hline
\end{tabular}

Table 5 shows the highly cited researchers who work in greater Munich, classified by discipline. The distribution of researchers by discipline is compared with that for researchers in the whole of Germany. As this comparison shows, researchers in greater Munich are particularly over-represented in "Molecular Biology \& Genetics" (14.23\%), "Space Science" (9.9\%) and "Physics" (8.68\%).

Table 6 shows the distribution of highly cited researchers who work in Germany by institution. It is apparent that the University of Heidelberg has the most highly cited researchers. But overall the Max Planck institutes dominate among the institutions. 
Table 6. Distribution of highly cited researchers from Germany by institution. The table only includes institutions with at least three researchers.

\begin{tabular}{|l|l|l|l|}
\hline Institution & Number & Per cent & $\begin{array}{l}\text { Cumulative per } \\
\text { cent }\end{array}$ \\
\hline University of Heidelberg & 8 & 4.88 & 4.88 \\
\hline $\begin{array}{l}\text { Max Planck Institute of Molecular Plant } \\
\text { Physiology }\end{array}$ & 6 & 3.66 & 8.54 \\
\hline University of Munich & 6 & 3.66 & 12.20 \\
\hline Technical University Munich & 5 & 3.05 & 15.24 \\
\hline European Molecular Biology Laboratory & 4 & 2.44 & 17.68 \\
\hline $\begin{array}{l}\text { German Research Center for } \\
\text { Environmental Health }\end{array}$ & 4 & 2.44 & 20.12 \\
\hline Max Planck Institute for Chemistry & 4 & 2.44 & 22.56 \\
\hline $\begin{array}{l}\text { Max Planck Institute for Polymer } \\
\text { Research }\end{array}$ & 4 & 2.44 & 25.00 \\
\hline RWTH Aachen University & 4 & 2.44 & 27.44 \\
\hline University of Bonn & 4 & 2.44 & 29.88 \\
\hline University of Frankfurt & 4 & 2.44 & 32.32 \\
\hline German Heart Centre Munich & 3 & 1.83 & 34.15 \\
\hline Hannover Medical School & 3 & 1.83 & 35.98 \\
\hline Max Planck Institute for Astrophysics & 3 & 1.83 & 37.80 \\
\hline $\begin{array}{l}\text { Max Planck Institute of Colloids and } \\
\text { Interfaces }\end{array}$ & 3 & 1.83 & 39.63 \\
\hline Max Planck Institut für Kohlenforschung & 3 & 1.83 & 41.46 \\
\hline $\begin{array}{l}\text { Max Planck Institute for Plant Breeding } \\
\text { Research }\end{array}$ & 3 & 1.83 & 43.29 \\
\hline $\begin{array}{l}\text { Helmholtz Centre for Environmental } \\
\text { Research }\end{array}$ & 3 & 1.83 & 45.12 \\
\hline University of Erlangen-Nuremberg & 3 & 1.83 & 46.95 \\
\hline University of Gießen & 3 & 1.83 & 48.78 \\
\hline University of Hohenheim & 3 & 1.83 & 50.61 \\
\hline University of Kiel & 3 & 1.83 & 52.44 \\
\hline University of Ulm & 3 & 1.83 & 54.27 \\
\hline Remaining institutions & 75 & 46.73 & 100.00 \\
\hline Total & 164 & 100.00 & \\
\hline & & & \\
\hline
\end{tabular}

\section{Discussion}

As the evaluations in this study show, the data from TR can, on the one hand, be used to investigate the distribution of research excellence in a country. The distribution in Germany is seen to be characterized by a high degree of concentration: In Germany, around half the researchers work in only two Federal States (Bavaria und Baden-Württemberg). Around a 
third of the researchers in Germany work in facilities which are located in only three cities (of their greater areas) - Munich, Berlin and Heidelberg.

On the other hand, the TR data can be used to perform evaluations with regard to disciplines. Here, the comparison of a subgroup with a whole can show in which disciplines researchers are over or under-represented. As the assessments for Germany show, researchers from Germany, compared with researchers a whole, are over-represented in "Plant \& Animal Science" as well as "Materials Science". In greater Munich, researchers in "Molecular Biology \& Genetics" as well as "Space Science" are over-represented in comparison with Germany as a whole.

Evaluations, as we have performed here for Germany, can provide interesting insights into the distribution of (subject-specific) research excellence in a country. 


\section{References}

Bornmann, L., \& Bauer, J. (in press). Which of the world's institutions employ the most highly cited researchers? An analysis of the data from highlycited.com. Journal of the Association for Information Science and Technology.

Gingras, Y. (2014). How to boost your university up the rankings, University World News. Retrieved from http://www.universityworldnews.com/article.php?story=20140715142345754

Myklebust, J. P. (2014). Meet the world's 3,215 hottest researchers. Retrieved July 1, 2014, from http://www.universityworldnews.com/article.php?story=20140626174600925 